\title{
Gene therapy on the move
}

Unexpectedly rapid advances in basic science suggest that gene therapy for a whole host of diseases will soon be a medical reality. The ethical dimensions - real and imagined - need to be sorted out.

THE intriguing notion that one might be able to cure genetic disease by giving patients a functioning version of a defective gene has been under consideration for the better part of two decades. At the outset, single-gene defects were the imaginary targets of would-be gene therapists who envisioned inserting functional genes into pluripotent stem cells in the bone marrow in order to cure a list of diseases that included sickle cell anemia, the thalassemias, the severe combined immunodeficiency disorders, and LeschNyhan syndrome.

But stem cells, few in number, have proved remarkably resistant to isolation and manipulation. Although recent studies suggest progress on the stem cell front, during the past few years investigators turned their hands to a host of alternative cellular vehicles for gene therapy.

Thus it was that lymphocytes (in this case tumour-infiltrating lymphocytes, or TIL) were enlisted for the first approved human gene experiment in the United States, which took place in 1989 at the National Institutes of Health (NIH), where Steven A. Rosenberg, W. French Anderson and R. Michael Blaese used TIL to carry a marker gene for Neomycin resistance into the tumours of patients in the terminal stages of melanoma. A year later at the $\mathrm{NIH}$, the same trio conducted the first trial of actual gene therapy when they transfused a little girl with adenosine deaminase deficiency (ADA) - a lethal immune disorder - with lymphocytes bearing the ADA gene, courtesy of a retroviral vector.

The ADA experiment (the child is doing well) is gene therapy in what was envisioned to be the classic case. By inserting the appropriate gene, which expresses an intended protein, one corrects a single-gene disorder.

However, in just the two years that human gene trials have been underway at the NIH, it has become clear that gene therapy is not just for single-gene disorders any more. Last week at an NIH conference simply titled "Human Gene Therapy", a record crowd of more than 550 researchers - academic and corporate alike - came away convinced that one day in the not too distant future, gene therapy will become a potent new force in medicine, with application to diseases as diverse as heart disease, cancer in its many forms, liver disease and diabetes - among others.

Claude Lenfant, director of NIH's Na- tional Heart, Lung and Blood institute (a co-sponsor of the conference), even predicted that gene therapy will eventually play a role in disease prevention, by correcting LDL receptor deficiency right after birth, for instance. And, of course, hope for the treatment of the major singlegene diseases such as cystic fibrosis (CF) was high. Francis Collins of Ann Arbor (co-discoverer of the CF gene with Tsui and Riordan of Toronto) put that in perspective, however, with this quote from the diary of an 8-year-old CF patient. Dated 25 August 1989, she wrote "Today is the best day ever in my life. They found a Jean for Cistikfibrosis." Of course, finding the gene - as Collins pointed out has not benefited the patient at all as yet, but, he predicted, it will one day soon.

The cellular vehicles for potential gene therapy are multiplying with unexpected speed, now including not only lymphocytes but also epithelial and endothelial cells, and myoblasts. In addition, retroviruses are yielding their primacy as vectors for gene insertion to DNA viruses (adenovirus in particular) and synthetic vehicles such as Ligand-PolylysineMinigene complexes.

The list of existing and pending gene therapy trials now stands in the US at six gene-transfer and five gene-therapy studies underway, with an additional seven likely to win approval early in 1992. One study has just been approved in the Netherlands. Many more are sure to follow.

All of this means that it is now particularly important to sort out the social/ ethical/policy issues that come up whenever gene therapy is mentioned. One of them is the 'mutant' issue, best dealt with by a patient who, after receiving a transfusion of genetically modified lymphocytes, quipped that it must be safe because "I haven't turned into a mutant."

In terms of responding to public fears about gene therapy, fear of the mutant, while groundless, should nevertheless be at the top of the agenda, according to Georgetown University Law School dean Judith Areen, who reminded the NIH conference that the ordinary person confuses Dr. Frankenstein with his monster, and that the two have been "fused in the public mind" with scientists of all disciplines. Combine that unhappy fact of life with the horrors of eugenics as advocated by Nazi Germany and it is easy to see why Areen says that, like it or not, gene therapists have what lawyers call the 'burden of proof' in this field of science and medicine."

Fears are widespread. Information is limited. All the more reason to make sure the public is privy to the decisions that are made. It is equally important that scientists discuss them clearly and in context. For instance, as Anderson acknowledges, the possibility that a retroviral vector will some day integrate next to a tumour suppressor and lead to cancer is real. "Sooner or later," he said, "some patient will get cancer [given the known imperfections of current vector technology]."

Should that inevitably put gene therapy on hold? Most would argue that it should not, presuming that the seriousness of the disease being treated and the absence of alternative therapies ethically justifies choosing risk in a risk-benefit analysis. What is important is that the public, to the extent that it cares to listen, be told exactly what the risks are - no more, no less. It is worth noting, here, that society already has ample experience in this area, even though it is seldom discussed openly in unambiguous language. Many chemotherapeutic drugs - drugs that have been used in cancer therapy for years - are themselves carcinogenic. Data show that patients who are cured on one cancer and live long enough are vulnerable to developing a new tumour attributable to the initial life-saving chemotherapy.

The point here is not that no ethical issue exists but rather that the ethical issue posed by the use of retroviral vectors in gene therapy is not entirely beyond existing medical experience and should be seen as part of a continuum.

Another so-called ethical issue is cost. Gene therapy trials, conducted for now in high-technology medical centers, are expensive. But cardiac surgery and transplantation therapy are surely equally expensive. If cost is an issue, it is not unique to gene therapy. Nor are questions about patient privacy, or reproductive rights, or the behaviour of insurance companies who want to exclude patients with genetic disease.

The discussion of ethical issues has, for the present, something of an abstract air about it. But that will not last. Once gene therapy is a real, practical part of medicine, the imaginary fears will probably evaporate, and the other issues will have to be faced just like any others in medicine.

Barbara J. Culliton 